\title{
The impact of Low Input Gardens on gardening systems, diet and livelihoods of urban poor households living with HIV and AIDS; A case of Mufakose high density suburb, Harare.
}

\author{
Makovere $\mathrm{V},{ }^{1}$ Nyamutowa $\mathrm{C}^{2}$ \\ 1. Midlands State University, Department of Natural Resource Management \\ 2. Midlands State University, Department of Agricultural Economics and Development, Zimbabwe
}

\begin{abstract}
Zimbabwe has a projected population of 12.7 million people and is among the countries in SubSaharan Africa worst affected by the HIV and AIDS epidemic. The estimated HIV prevalence among adults 15 years and above is $13.1 \%$ according to the UNAIDS (2011). The Government of Zimbabwe (GoZ) and civic organizations have supported therapeutic and supplementary feeding of children and adults living with HIV who suffer from moderate to severe malnutrition. Urban agriculture has for years served as a vital strategy to enhance food security of many poor urban households in Zimbabwe. Traditionally, urban agriculture focused on the production of green vegetables and fruits with the staple maize being accessed from the market. The purpose of this study is to evaluate the impact of Low Input Gardens on urban vegetable production systems, its effect on household dietary diversity and lives and livelihoods of urban poor HH affected by HIV and AIDS. Random sampling in survey site of Mufakose Harare high density suburb were NGOs are active in urban and peri-urban agriculture. $N=350, n=65$ using the Bartlett, Kotrlik and Higgins (2001) tables. A household dietary diversity interview was done on the sample of households. The results showed a higher dependency on nutrition gardens on females than males with 57\% of the households composed of widows and single parents as a result of the effects of HIVIAIDS. Household ownership has an effect on the level of adoption of urban agriculture. Urban poor households have limited resources and therefore have limited access to quality inputs for use in their gardens including seed. Provision of seed starter packs by NGOs for uncommon nutritious vegetables had an effect of the variety of crops after LIG. It was shown that there is a positive relationship between capacity building programs and the improvement of livelihoods by the urban households.
\end{abstract}

Key words: urban agriculture, Zimbabwe Mufakose, HIV/AIDS, nutrition, low input gardens.

\section{Introduction}

Zimbabwe has a projected population of 12.7 million people and is among the countries in SubSaharan Africa worst affected by the HIV and AIDS epidemic. The estimated HIV prevalence among adults 15 years and above is $13.1 \%$ according to the UNAIDS (2011). There are an estimated 1,159,097 adults and children living with HIV and AIDS in Zimbabwe according to the National Aids Council national report (2012). To date, an estimated population of 597,293 adults and children are in urgent need of antiretroviral therapy.

According to the Global AIDS response progress report (2012), the prevalence of HIV in Zimbabwe has generally been on the decline from $23.7 \%$ in 2001 to $18.4 \%$ in 2005 and further declining in 2011 to $13.1 \%$. The decline is attributed to successful implementation of prevention strategies especially behavior change, high condom use and reduction in multiple sexual partners. In addition, high mortality due to low Anti-Retroviral Therapy (ART) coverage has also contributed to the decline in the prevalence rate. Meanwhile, Anti-Retroviral Therapy (ART) coverage has increased from 55\% in 2009 to $79.7 \%$ in 2011

Nutritional health is essential for People Living with HIV and AIDS (PLWHA) for them to get the most out of the period of asymptomatic infection. This is essential for effective immune response to fight opportunistic infections and to optimize benefits of ART. The association of malnutrition with opportunistic infections which is further aggravated by HIV and AIDS is a significant factor among adults and more severe among children who are living positively with the HIV virus. The Government of Zimbabwe (GoZ) and civic organizations have supported therapeutic and supplementary feeding of children and adults living with HIV who suffer from moderate to severe malnutrition.

Urban agriculture has for years served as a vital strategy to enhance food security of many poor urban households in Zimbabwe. This has especially been important to poor urban $\mathrm{HH}$ with bread winners living with HIV and AIDS who have in some instances lost their jobs due to ill health. Traditionally, urban agriculture focused on the production of green vegetables and fruits with the staple maize being accessed from the market. Generally, urban dwellers were relying on the market for food but with the tremendous surge in food prices beyond the reach of the majority especially after the turn of the century, poor urbanites in Zimbabwe have resorted to intensifying urban agriculture as a coping strategy to meet their immediate food requirements 
(Kutiwa, 2010). Urban agriculture is generally labour intensive, and as such creates work opportunities which keep poor urbanites busy (Kuchelmeister, 1998). Urban agriculture can loosely be split into two categories, agriculture for the production of the staple maize and agriculture for vegetable production. Urban agriculture for the production of maize is limited to small plots outside the home and is normally rain fed whilst vegetable production is confined to the household yard and areas around the household $(\mathrm{HH})$ yard and entails production of high value crops like onions, beetroots and green vegetables. The vegetable garden is normally irrigated using piped water.

The civic society which includes non-governmental organizations have been complementing Government's efforts through awareness campaigns, supporting home based care initiatives, supplementary feeding and increasing access to treatment and ART for people infected by HIV and AIDS and actionaid International Zimbabwe is one such non-governmental organization. Actionaid International Zimbabwe [AAIZ] is a global federation committed to finding sustainable solutions to end poverty and injustice. With 43 affiliate, associate and country program members worldwide, AAIZ focuses the majority of its resources on working with millions of the poorest and excluded women, men and children, making long-term commitments to advance their human rights and to transform the world in which they live in. In this spirit, AAIZ has been supporting urban poor households living with HIV and AIDS under the Protracted Relief Programme [PRP] II, Urban Poor Communities Responding to HIV and AIDS and Poverty Programme, for the past three years in the high density suburb of Mufakose. In a participatory review process that was done prior to project inception, it was observed that one of the major issues affecting People Living with HIV and AIDS (PLWHA) is access to good nutrition. At the peak of Zimbabwe's economic crisis in 2008, AAIZ responded to this need through direct food distributions in Mufakose. However, this approach was not sustainable as it created a dependency syndrome by beneficiaries who in subsequent years showed reliance on external support. An all stakeholder engagement resulted in the identification of Low Input Gardening (LIG) as one of the sustainable strategies to ensure poor people especially those living positively with HIV and AIDS respond to and access good nutrition and become resilient in dealing with the difficulties that usually manifests where access to good nutrition is compromised. Low input gardening acknowledges the limitations of water and space in urban areas and therefore emphasizes on intensification of gardening operations on small pieces of land (Municipal Development Partnership for the East and Southern Africa (MDP-ESA), 2009). The review process identified that even very poor urbanites practice gardening on small patches of homestead land, vacant lots, roadsides edges, or in containers. With the LIG approach gardening can be done with very little economic resources, using locally available materials like organic manures, live fencing and incorporating indigenous methods of pest control (Mbiba, 1993), thus LIG is a production system that the poor can easily adopt with success.

To roll out this project, AAIZ went on a massive capacity building exercise targeting community based organizations, government departments like the Department of Agriculture, Technical and Extension Services (Agritex) and individuals. Capacity building strategies included trainings and mentoring of organizations and individuals in principles of LIG and the associated benefits of adopting it. AAIZ also created shared learning platforms like exchange visits and fairs to enhance adoption through showcasing of best practices. The expected output of these actions was to create nutrition security among poor urban households (HH) and overally contribute to $\mathrm{HH}$ food security.

\section{Contribution of Low Input Gardens to food and nutrition security}

Generally, home gardening contributes to household food security by providing direct access to food often on a daily basis (Marsh, 1998). Low input gardening provides a diversity of fresh foods that improve the quantity and quality of nutrients available to the family. Households with gardens typically obtain from them more than 50 percent of their supply of vegetables, fruits and medicinal plants and herbs (UNDP, 1996). A well maintained LIG can supply a variety of mixed vegetables which can provide a significant percentage of the recommended dietary allowance for protein $(20 \%)$, iron $(20 \%)$, calcium (20\%) and vitamins $(90 \%)$ (Marsh and Talukder, 1994).

\section{The role of nutrition in HIV management}

HIV-positive persons have been shown to have an increased risk of HIV progression and mortality when they are malnourished (Drain PK, 2007). There is strong evidence that malnourished people are less likely to benefit from antiretroviral treatment. Also according to Drain (2007) patients with mild malnutrition (body mass index just below $<18$ ) were twice as likely to die in the first three months of treatment. For those with severe malnutrition (body mass index $<15$ ) the risk was six times greater than for those of healthy body weight (body weight index between 18 and 22). Mortalities in the first three months of starting antiretroviral treatment are highest (95\%) among the most severely malnourished. Without food or the right nutrition, taking antiretroviral drugs can be so painful that people simply don't take them (Marston B, and De Cock KM, 2004). 
One responded in an interview with Drain (2007) said that taking antiretroviral drugs on an empty stomach is like digesting razor blades.

\section{Legislation governing urban agriculture in Zimbabwe}

There is no written policy on urban agriculture especially in relation to it being both an economic and sustainable livelihood activity (Mushayavanhu, 2010). There has been however a policy shift in that the local authorities now support urban agriculture as long as it is controlled and is being done systematically. It is important to note that policy incoherence has led to ad hoc response to the promotion or banning of urban agriculture (Mudimu, 1998). The Nyanga Declaration on Urban Agriculture in Zimbabwe and the Harare Declaration by Ministers of Local Governments in Eastern and Southern Africa on legalizing urban agriculture pave way for future specific law making in the field of urban agriculture.

The practice of urban agriculture is not illegal. It only becomes illegal when it is not authorized as well as when it is done along stream banks and protected wetlands (Mudimu, 1998). The laws that regulate urban agriculture and wetlands conservation include the Water Resources Act of 1927 which regulates activities that interfere with stream banks or with wetlands. The Natural Resources Act of 1952 prevented land degradation and vegetation clearance in both wetlands and along stream banks as well as the Salisbury (Protection of Lands) By-laws of 1973, Rhodesia Regulations No: 104 of 1973 that were passed in terms of section 279 of the Municipal Act Chapter 125 to forbid all cultivation on municipal land that is done without its prior approval. The by-law sanctioned the destruction of crops cultivated on uncontrolled lands. Some of the regulations also include Harare Noise By-Laws SI 109 of 1979, the Keeping of Animals By-laws of 1962 and SI 5 of 1990 that regulates tree nurseries.

The Urban Councils Act governs local authorities and empowers the Minister of Local Government to make regulations governing urban agriculture, such as the Protection of Public Sewers Act, Public Drains and Water Mains Act: Section 180 (1) (b) and Section 186 (1) (b). Under the Urban Councils Act, the Council can lease, donate, sell or exchange land. Under Section 198, Council also has the power to grow crops, keep livestock, enter upon any land and clear any crops or livestock being grown illegally or which constitute a fire or public health hazard. The Water Act is important in that it deals with water quality as well as water resources planning and development. This law requires catchment councils to prepare outline plans. These plans are also drawn in compliance with the Regional, Town and Country Planning Act [29:12].

The Environmental Management Act (EMA) tries to accommodate community participation as well as the promotion of environmental rights in line with provisions of sustainable development as defined by agenda 21. EMA attempts to co-ordinate all laws that address environmental issues. It recognizes the important role played by local authorities in environmental conservation as planners, service providers, issuers of permits, as polluters in their own right, as law enforcement agencies and appropriate authorities. Although the Regional, Town and Country Planning Act is silent on urban agriculture, it supports agriculture which is incorporated in local and regional plans. Land use in Zimbabwe is planned in terms of Master and Local Plans administered under this Act.

Section 3 of EMA provides that, "if any other law is in conflict or inconsistent with this Act, this Act shall prevail." The provision has overriding effect over all other enactments. Section 143 repeals the Natural Resources Act (Chapter 20:13). EMA also provides for the formation of an Environmental Management Agency whose functions include developing guidelines for the preparation of a National Plan, environmental management plans and local environmental action plans. Its functions are consistent with the Town and Country Planning Act (Chapter 29:12) which invites the public to raise objections in relation to the National Plan proposals through a notice in the Gazette and requires local authorities to develop local authority environmental plans. The Minister may make an order for protection of environment in respect of preservation or protection of beds, banks or course of a public stream or a water source. The order can also determine the prohibition or restriction of cultivation or use of the land and limiting the use of agricultural pesticides. Regulations on urban agriculture are enacted in terms of section 140 of EMA. These include the control or prohibition of activities and practices likely to cause pollution to the environment, the prohibition or restriction of the cultivation of land, the banks of public streams or adjacent to artificially conserved water and the conservation, protection of wetlands and of the bed, banks or course of any river or stream and any source of water and the destocking and limitation of the number of livestock or domestic animals on land.

\section{Weaknesses of the laws}

The laws governing urban agriculture are fragmented and there is an absence of laws and policies that are specifically dedicated to regulating and monitoring urban agricultural activities according to Mushayavanhu (2010). Furthermore, institutional functions in respect of urban agriculture are uncoordinated. Although the law makes it mandatory for certain projects to be subject to environmental impact assessments, both urban agriculture and change of land use for purposes of agricultural production are exempted from projects that 
require impact assessment. This means neither urban agriculture nor the conversion of land into agricultural purposes is not subject to impact assessments. However, forest land should be subjected to an environmental impact assessment if it is converted into other use. Thus, EMA is flawed in that land use and its conversion are not addressed despite it being a major source of most environmental problems such as land degradation and soil erosion.

\section{Gaps of the present legislation}

Tenure arrangements - Mbiba (1993) noted that access to land in urban areas is informal, and ownership is by donations from relatives and friends, through inheritance, patronage, and continuous practice, length of stay in area or living within a certain community, ethnic background and the identification of vacant land. The lack of clear definition of tenure systems in the form of leases and permits has resulted in conflicts among the various land users (Bowyer, 2001). There are divergent claims and competing interests and conflicts over issues of access and control and use of land resources. Bowyer (2001) also noted that there is pressure for land due to land invasions, developers, residential stands, industrial stands and conflict between customary law and statute law. The identification of appropriate farmers will ensure that they have some degree of both security and certainty of land tenure. Secure tenure systems need not be permanent land tenure since land use needs are constantly evolving with urban growth in urban areas. It should be secure land tenure for a period of time given to a needy household. This can be through lease agreements based on land use development plans for the city. In rural or peri-urban areas, access to land is characterized by customary, public and private tenure arrangements. It is important to note the legal implications of these systems in dealing with access issues.

Sustainable development - Mushayavanhu (2010) stated that improving access for the poor urbanites is in line with the concept of sustainable development. This principle can be traced to the 1972 Stockholm Conference on Human Environment. It was institutionalized through the Brundtland Commission of 1987, and operationalised through Agenda 21. The principle entails two concepts, on one hand meeting the needs of the poor people and on the other hand, imposing technological limitations (Bowyer, 2001). EMA has adopted most international environmental emerging principles and it promotes community participation in environmental governance. It is therefore important that various key stakeholders should take part in formulating policy and laws that regulate urban agriculture. The Harare City Council has adopted a Local Agenda 21 on paper. What is required is to operationalise it so that issues such as poverty reduction could be addressed in the context of urban agriculture.

\section{Statement of the problem}

The purpose of this study is to evaluate the impact of Low Input Gardens on urban vegetable production systems, its effect on household dietary diversity and lives and livelihoods of urban poor $\mathrm{HH}$ affected by HIV and AIDS. The research seeks to answer questions on changes in vegetable production systems, changes in the diets of urban poor and changes in income and livelihoods of households adopting urban-periurban agriculture.

\section{Justification}

The role of good nutrition in the management of HIV and AIDS has assumed increasing importance over the past decade. The World Health Organization (2005) agrees that nutritious food is one of the most powerful weapons available for fighting the often calamitous effects of AIDS. Furthermore, it has been clinically confirmed that malnutrition is the fatal manifestation of AIDS for many people who succumb to the disease (Romeyn, 2009). People Living with HIV and AIDS (PLWHA) may require up to twice the normal daily caloric intake to protect themselves from the dangers of HIV-related malnutrition, heightened immune suppression, muscle wasting and outright starvation due to mal-absorption and abnormal metabolism of nutrients (Kaiser, 2005). Appropriate diet can significantly reduce both the side effects of medication and the symptoms of opportunistic infections (Romeyn, 2009).

AAIZ through its partners and other stakeholders has been responding to the need for a balanced diet by poor and vulnerable PLWHA in Mufakose through the promotion of sustainable low input gardens. The major objective of this action is to reduce the effect of HIV and AIDS through building resilience of PLWA to respond to their nutritional needs. On the whole this intervention has resulted in an improvement in the quality of life of PLWHA from low and medium quality of life to high quality of life, according to the AAIZ quality of life index report (2011). This change can however not be wholly accredited to the LIG intervention alone as other benefits like the creation of support groups for psychosocial support also contributed to this result. Community Home Based Care (CHBC) initiatives also greatly contributed to a better quality of life for PLHWA. CHBC focused on improving care and support for PLWHA and also encouraged the adherence to treatment by PLHWA.

Firstly, this research wants to track changes in urban gardening systems that have been adopted by poor urban people after embracing the principles of LIG. Secondly, the research seeks to qualify and quantify 
the changes in the household diets and how these are now contributing to HH nutrition security. Thirdly the research wants to access how the benefits of LIG have impacted on the lives and livelihoods of urban PLHWA in Mufakose. Finally, this research will come up with recommendations to policy makers and urban planners on the importance of LIG and urban agriculture and how these can be revitalized to circumvent poor nutrition and threatening food insecurity among urban poor households affected by HIV and AIDS. Thus, this research will contribute to the basis of advocacy for the recognition of urban agriculture at town planning and policy making levels.

\section{Sampling method and sample size}

\section{Methodology}

The survey site is Mufakose high density suburb located to the South West of Harare. This site was chosen because it is where AAIZ implemented the Low Input Gardening innovation. The target for this research are beneficiaries, volunteers, partner organization staff and stakeholders. Beneficiaries in this context are those $\mathrm{HH}$ which benefited directly from the project through trainings, material support and shared learning initiatives like exchange visits and fairs. Partner organization refers to New Dawn of Hope, an implementing partner for AAIZ based in Mufakose and stakeholders are other organizations and individuals with an interest in urban agriculture and include Government departments like Agritex, the City Council and the Ministry of Health. Beneficiaries and volunteers will be interviewed through Focus Group Discussions (FGDs). The sample size of 65 from a population of 350 was reached using the Bartlett, Kotrlik and Higgins (2001) tables which were designed using the Cochran formulas. A household dietary diversity interview will also be conducted for the 65 selected beneficiary HHs. The food groups will be divided into 16 food groups as recommended by FAO (2007) in order to get a deeper analysis of the dietary diversity. The scores will then be consolidated in to the standard 12 food scale.

\section{The Household Dietary Diversity Score}

The household dietary diversity is a qualitative measure of food consumption that reflects household access to a variety of foods. It is a proxy of nutrient adequacy of the diet of individuals (FAO), 2007). It reflects in a snapshot, the economic ability of a household to access a variety of foods. An increase in dietary diversity is associated with socio-economic status and household food security (Hoddinot and Yohannes, 2002). A reference period of the previous 24 hours is normally used.

\section{Results, Discussion and recommendations}

\section{Results, Findings and Discussion}

The project target group was urban poor households infected or affected by HIV and AIDS. The targeted group generally has a high number of females than males mostly because more males generally succumb to HIV more than their female counterparts (UNAIDS, 2001). This is confirmed by $74 \%$ females and $26 \%$ males who were direct beneficiaries of this project. $25 \%$ of these are married, $2 \%$ are single, $16 \%$ are divorced, $54 \%$ are widowed and 3\% are single parents. The high number of widowed $\mathrm{HH}$ is also an indicator of the erosion of $\mathrm{HH}$ livelihoods as the deceased are mostly bread winners in the HH who are mostly males. It is also interesting to note that urban poor HH affected by HIV and AIDS are mostly female headed constituting $54 \%$ whilst $27 \%$ are male headed, $16 \%$ are elderly headed and $3 \%$ are child headed. $\mathrm{HH}$ size ranges from 2 to 12 members with an average family size of 6 members. This implies that they need a vegetable garden of $20 \mathrm{~m}^{2}$ or more for them to meet their daily vegetable need s according to Nyamanhindi (2011). The average age of beneficiaries is 43 years with the majority in the range 31 to 50 years, the most productive period of any human being's life.

$49 \%$ of urban poor HH living with HIV just have a basic primary education, with $32 \%$ having gone through to secondary level. However of those only $6 \%$ manage to go to tertiary level education. This has a direct effect on their livelihoods as a low education compromises their chances of securing a stable and good paying job. This relegates them to engaging in self jobs like vending (53\%) and also menial piece jobs in the community like doing laundry and weeding in the fields $36 \% .11 \%$ depend on donations/remittances from well wishers and relatives Some respondents also confessed to engaging in illegal activities for a living and of prominence were the selling of illicit drinks, selling of cannabis, and prostitution.

$58 \%$ of people reached by the LIG intervention are home owners either individually or jointly. It is also interesting to note that all became homeowners through inheriting houses from parents who were mostly of foreign decent (Zambians and Malawians). This made them have easy access household backyard gardens. The remaining $48 \%$ live on rented properties and don't have ready access to gardening space in the household yard. This group is also very mobile and makes it difficult for them to establish a new garden each time they change their place of residence. Through the project, they are accessing gardens through community gardens in school yards or in open council spaces. $45 \%$ of poor urban gardeners rely solely on council water for irrigation. With 
the erratic supply of council water, this has greatly compromised garden output to this group of gardeners. $16 \%$ rely solely on borehole water for irrigation. These are those gardeners in community gardens situated at schools or in open council land. $97 \%$ direct beneficiaries of the LIG project received training either directly from AAIZ or its partner or through volunteers. $95 \%$ received a starter pack which were in the form of 10 different vegetable species and hand tools which included a garden fork, a wheel barrow and a spade. Periodically, all beneficiaries received technical support either directly from AAIZ and partner, or from the Department of Agritex. $56 \%$ of beneficiaries participated in exchange visits, shows and exhibitions which show cased best practices and created opportunities for sharing experiences.

\section{Changes in the vegetable production system}

Changes in the vegetable production was assessed based on such LIG practices like seed retention, the use of organic manures, cultural control of pest and diseases, the use of natural sprays to control pests and diseases, the minimum use of synthetic fertilizers and agro chemicals among others. Changes in the vegetable production system were also assessed through changes in the cropping mix.

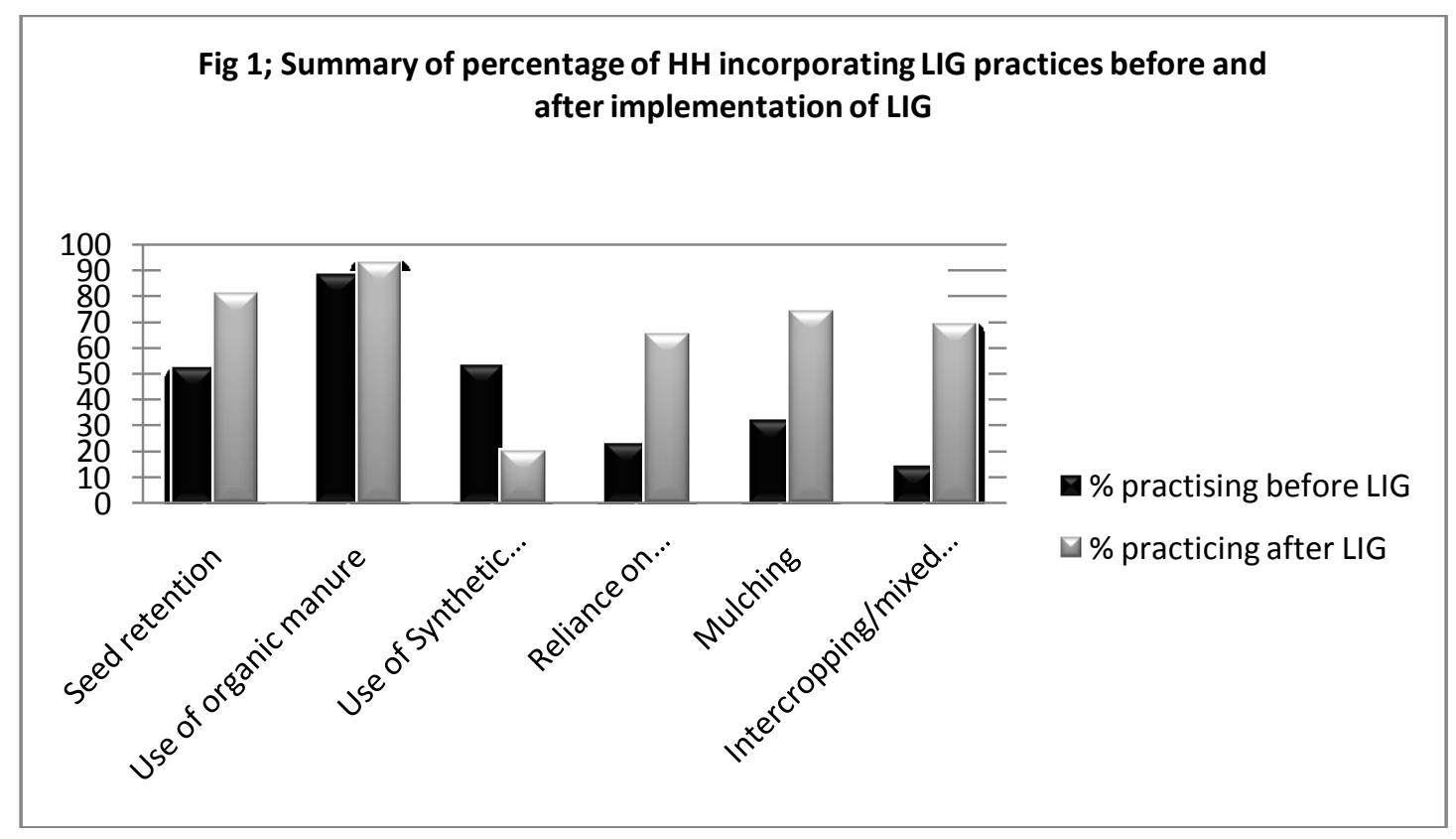

Urban poor households have limited resources and therefore have limited access to quality inputs for use in their gardens including seed. As a coping strategy, $52 \%$ such households have been retaining seed for use in the next planting. To increase the quality of such retained planting material, gardeners were trained on how they can effectively select seed right from the time of planting. This as a low input technique ensured urban poor households had access to good quality planting material with no direct monetary costs. This resulted in the increase in the number of urban poor households practicing seed retention from $52 \%$ before LIG to $81 \%$ after $\operatorname{LIG}(\mathrm{P}=0.001)$.

Also a significant change was recorded in the use of natural sprays for the control of pests and disease which increased from $23 \%$ to $65 \%(\mathrm{P}=0.413)$ of poor urban gardeners. Initially, the use of natural sprays for control of pests and diseases was mostly used when people couldn't afford to buy commercial agro-chemicals. After LIG, there is now appreciation of the dangers caused by the use of strong agro-chemicals in terms of their quality on food and on the environment. Commercial agrochemicals like pesticides are now only used when natural sprays are have failed to effectively control the targeted pests. The most common natural sprays are chilly, garlic, pawpaw leaf and tephrosia leaf sprays.

Mulching, a soil and water conservation practice has also been embraced as a result of LIG. The practice has seen an increase in popularity from $32 \%$ before LIG implementation to $74 \%(\mathrm{P}=0.29)$ among poor urban gardeners. The other driver of mulch being so popular is the erratic supply of water especially in the high density suburbs which puts pressure on people to conserve water.

The changes in the crop mix before and after the implementation of the LIG project was also used as a basis to assess the changes in the vegetable production. Before implementation of the LIG, urban gardens were characterized by the monocropping of covo and tsunga mostly, with small patches of tomatoes and onions. The crop mix only had at most 2 to 3 species at a time and the introduction of low input gardens has seen gardens with an average of 5 species at a time. The species of crops are selected 


\section{Fig 2; Comparison of crops grown before and after LIG}

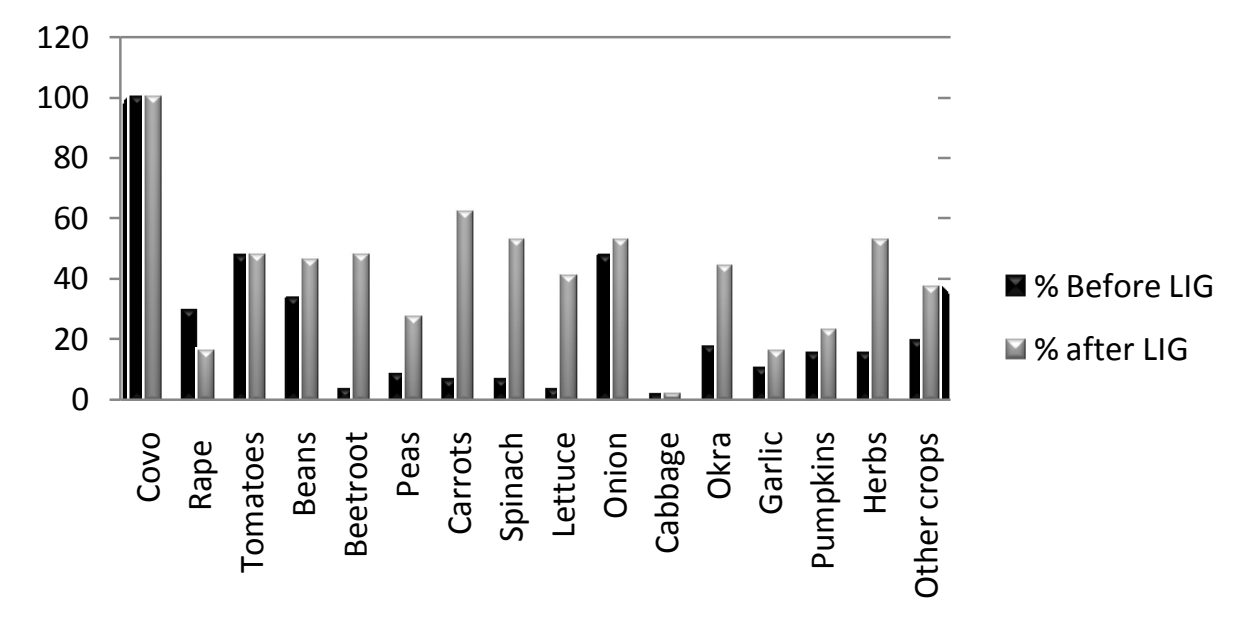

and arranged in such a manner that they benefit from each other either for example covo and onions where onion repel pests especially aphids and the onions utilizes the spacing between covo plants. The percentage of farmers practicing some intercropping/mixed cropping increased from $14 \%$ before LIG to $69 \%$ after LIG $(\mathrm{P}=$ 0.435). LIG also emphasizes on the diversity of crops in the garden to ensure HH members meet their dietary needs. This is especially important for PLWHA who need $10 \%$ more nutritional requirements than a healthy person. This also motivated the poor urban gardeners living with HIV and AIDS adopt to LIG as it ensured they also get the nutritional nourishment they so desired. A comparison of the most common species of garden crops was done and the results are as shown in Fig 3. After LIG, most species were appreciated more and this saw an increase in the number of $\mathrm{HH}$ growing them in their gardens. The crops that were appreciated more and were grown more after implementing LIG are beans, beetroot, carrots spinach, lettuce okra and herbs (all had P $>0.05$; see table 3). This was mostly because HHs were given these species in the starter pack from which they grew and utilized these species and also that HHs now knew how nutritionally good these species were. Also trainings on utilization added to the appreciation of these species and led to them being grown more in the gardens. Cabbage growth remained low as it is considered a crisis vegetable. It is less palatable and can also be cheaply available from the market. Rape actually experienced a reduction in the number of HHs growing it after LIG from $30 \%$ down to $16 \%(\mathrm{P}=0.427)$. This was so because rape is easily attacked by pests especially aphids which would be a complication in a LIG as there has to be minimal use of pesticides.

An increase from $20 \%$ to $37 \%(\mathrm{P}=0.614)$ was also noted on other vegetables. This was mostly as a result of more appreciation of the superior nutritive value of traditional vegetables like amaranths, cleome, sweet potato leaves and cow pea leaves. Herbs are also now common in LIG gardens. These are grown for culinary purposes which are important to PLWHA who often have digestive upsets due to the side effects of ARVs or due to opportunistic infections. Herbs are also used in the preparation of natural sprays and as repellents in the control of pests and diseases in a LIG. Herb presence in gardens increased from $16 \%$ before LIG to $53 \%$ after $\operatorname{LIG}(\mathrm{P}=0.538)$

On the question why they didn't grow some these species they are growing, $48 \%$ responded that they didn't know how to grow them before LIG, 15\% said they didn't know how to utilize them before LIG, $29 \%$ said they didn't have access to planting materials and $8 \%$ said they had never thought of growing them before until they were give as a starter pack.

Changes in the diet 
Fig 3; Consumption

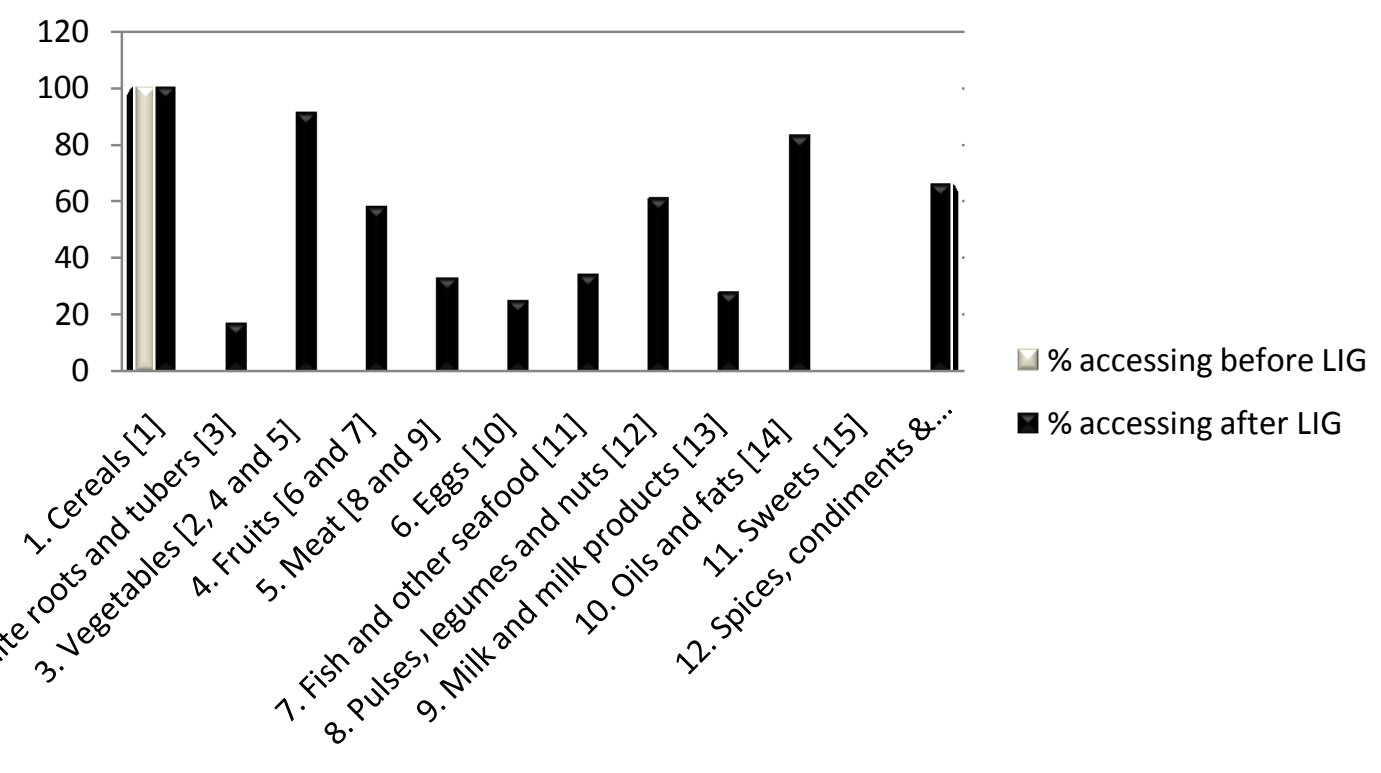

According to the household dietary diversity score (HDDS) by FAO (2007) a score less than 4 is low, a score between 4 and 6 is medium and any score seven and above is high. Before the implementation of LIG, the average HDDS for urban poor households living with HIV and AIDS was 3.6 which was low. This was raised to 5.9 after the implementation of LIG which is in the medium category. It was also interesting to note that an increase in garden also had a positive effect on the consumption of other food likes like meat, fruits and milk. This was justified by the fact that if own production is increased, money that otherwise would have been spent on buying vegetables would be spent on acquiring other foods like fish, meat and fruits as indicated by an increase in consumption of these. Of note is the increase after LIG of the consumption of white roots and tubers from $0 \%$ to $17 \%$, fruits from $27 \%$ to $58 \%$, meat from $9 \%$ before LIG to $33 \%$ after LIG, pulses and legumes from $27 \%$ to $61 \%$, milk and milk products from $10 \%$ to $28 \%$ and beverages and spices from $27 \%$ to $66 \%$.

Impacts of low input gardens to households

The table below shows the qualitative perception of the benefits of LIG to the households

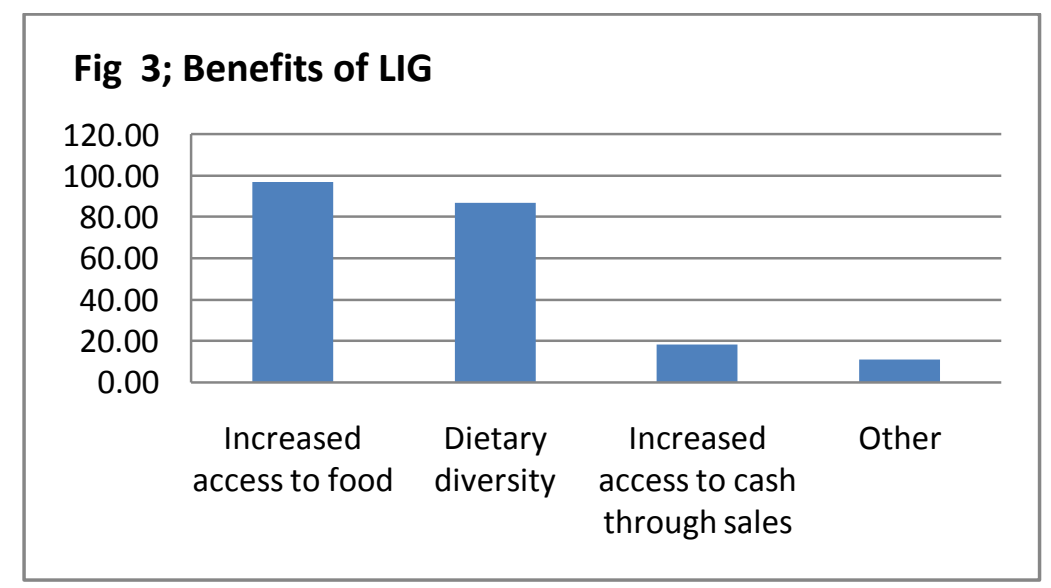

A total of $88 \%$ of $\mathrm{HH}$ implementing LIG meet all their vegetable needs through own production. Of these, $45 \%$ produce a surplus which they sale realizing an average monthly income of USD\$10. This money is used to buy groceries like soap, sugar, cooking oil and other household necessities and is used as it comes. The average income of the targeted group is USD $\$ 65$. Therefore income from garden sales accounts for $15 \%$ of the average monthly household income. As a result of this, $97 \%$ of $\mathrm{HH}$ answered positive to the question that LIG has increased their access to food. However the nutritive benefits of the dietary diversity are difficult to quantify in 
monetary terms. Some $87 \%$ answered positive to the fact that adopting LIG increased that diversity of food they were consuming in the household. This gave them a piece of mind a key attribute to healthy living, as they were assured of relish and they had time to concentrate on other livelihood activities instead for looking for food.

Table 1 Qualitative attributes of the impact of Low input gardens

\begin{tabular}{|l|l|l|}
\hline Qualitative attribute & ranking & Value \% \\
\hline Feeling of empowerment & 2 & 55 \\
\hline Nutritional security & 1 & 85 \\
\hline Peace of mind & 3 & 80 \\
\hline Dignity & 4 & 35 \\
\hline Other factors & 5 & 5 \\
\hline
\end{tabular}

The following qualitative measures real that $18 \%$ of those who produce a surplus agreed that the amount of money they got from sales was significant and it gave them the ability to access other foods like eggs and fish (matemba) and also to be able to buy other $\mathrm{HH}$ necessities like sugar salt and cooking oil. 54\% also agreed that LIG had empowered them. It boasted their self confidence and they had transformed from being recipients to being donors as they can now also give their peers bundles of vegetables. 34\% said LIG gave them back their dignity as they were now better accepted by others.

On the negative impact side, they has been stigmatization of the communal gardens. This has impacted negatively on some $\mathrm{HH}$ who have since stopped participating in the gardens. $6 \%$ of garden dropouts sited stigmatization as reason for their withdrawal from participating in the garden activities.

\section{Conclusions}

More females participate in gardening than males. This is because in a HH setup, women are directly responsible for the day to day food issues and therefore are the ones who feel the pressure when food is scarce within the HH. In most HH affected by HIV and AIDS, the surviving spouse is the woman. Most of these women only have a basic education up to primary level. They therefore struggle to secure decent jobs plunging them into further poverty as soon as the husband, who is normally the bread winner passes on. As a survival strategy, these women have engaged in self help income generating activities the most common being cross border trading and vending. As a result of these hard times, some women have been pushed into engaging in illegal activities like prostitution and selling of elicit substances.

Most poor urban HH live on rented property. This group is very mobile as they and they change places of residence an average of two times a year. This makes it difficult for them to establish very good diverse gardens as they are always on the move. Also most of these have limited access to gardening space at their places of residence as they are very small spaces for gardening which are mostly for the landlord. All beneficiaries show a good understanding of LIG principles and their applications confirming the fact that trainings and mentoring was very effective.

They were changes to urban vegetable production as a result of HH adopting LIG principles. Of special note is the adoption of soil and water conservation practices like mulching, the increased use of natural sprays for pest and disease control and the reduced use of agrochemicals and synthetic fertilizers. A change in the production system was also noted in the type of crops grown. Through LIG, garden species grown have evolved from the traditional covo dominated garden to a diverse garden with a significant presence of carrots, spinach, lettuce, beetroot and a variety of herbs. The utilization of traditional vegetables like amarathus, nyeve, cow pea leaves and sweet potato leaves also increased as they are now not being considered starvation foods. Some of these were regarded as weeds before LIG but now there is a marked presence of these in gardens as they are left to grow and are used utilized.

Household dietary diversity has increased significantly from low diversity to medium diversity as a result of adoption of LIG. Further expansion of gardens has however been limited by restrictive gardening space and the now persistent water problems in urban areas. This has limited production with most $\mathrm{HH}$ only producing enough for their consumption. Income realized from the sale of surplus from the garden contributes significantly to the total $\mathrm{HH}$ income. This type of income is also significant in that it also the only independent source of income for most women as it is not controlled by men. This money because it is controlled by women is channeled directly towards meeting immediate food requirements. An increase in vegetable production where a surplus is produced and sold has the effect of an increase in other non garden foods like fish (matemba), milk and meat.

The major benefit of increased and diverse garden production has had the benefit of increased access to food by poor urban $\mathrm{HH}$. This has also affected eating habits where $\mathrm{HH}$ eat an average of two solid meals due to the availability of diverse vegetables in the garden.LIG empowers $\mathrm{HH}$ to be self sufficient and restoring their human dignity as no longer rely $\mathrm{n}$ donations for survival. It also results in improved quality of life because of a balanced nutrition and a peace of mind. HH members can engage I other livelihood options instead of 
concentrating on gathering food for immediate consumption. This increases overall household income and also contributes to the overall quality of life for the household.

And lastly, community gardens if targeted at only the poor and PLWHA are stigmatized.

\section{Recommendations}

There is no legislation that supports urban agriculture in Zimbabwe. To ensure that the full potential of LIG and urban agriculture in reducing food insecurity and poverty is fully realized it is recommended that policy makers come up with policy that dictates LIG and urban agriculture framework. Policy should include the integration of agriculture in city development plans and incorporating agro-residential planning in city development plans.

Urban agriculture is heavily susceptible to pollution from uncollected waste, effluent from industry, burst sewer pipes and exhaust smoke from vehicles. I therefore recommend that intensive environmental health education and awareness campaigns be done in urban areas to conscientise urban farmers on the potential risk of contamination they face.

An effort to ensure poor $\mathrm{HH}$ who don't have access to home gardens get gardening space in communal gardens has seen these gardens being stigmatized. To help reduce stigma, selection of beneficiaries should also target progressive members of the community who have the confidence to quickly take up new ideas. This instills confidence in the poor $\mathrm{HH}$ and helps them take up new ideas from their fellow progressive peers since most poor people are slow adopters of new ideas.

Gardening is confined to small pieces of land due to limited space in urban areas. Though intensive cropping has been emphasized under LIG, it should also be taken further to include only the production of high value crops which can be easily sold. A good example is mushroom which can be grown over a very small area of land with high monetary returns.

Since it has been noted that most poor urban $\mathrm{HH}$ are lodgers and are very mobile, mobile gardens is a good option. Mobile gardens can be made from used bags, bins or old dishes. Good quality soil and manure is put into these containers and vegetables are sown. When the HH is on the move, they then can also move with their garden and don't need to necessarily start establishing a new garden. Such gardens are also very efficient in water conservation.

\section{References}

[1] Almar (2000) Urban Agriculture and Food Security, Nutrition and Health. In Bakker et al.(Eds.): Growing Cities, Growing Food. Germany. Feldafing-DSE. Pg100-110.

[2] Bartlett J.E. Kotrlik J.E. and Higgins C.C. (2001) Organizational Research: Determining Appropriate Sample Size in Survey Research. Information Technology, Learning, and Performance Journal Vol. 19. No.1.

[3] Bowyer B. (2001) Conflicts For Resolution And Suggestions For Consensus: Legalising Urban Agriculture In Harare. University Of London. UK.

[4] Cattleman T. Seumo-Fosso E. and Cogill B. (2003) Food and nutrition implications of antiretroviral therapy in resource limited settings. Washington DC. FANTA Project.

[5] Corbet J.(2006) Multi-storey gardens to support food security. University of Washington.

[6] Drain P.K.et al (2007) Micronutrients in HIV-positive persons receiving highly active antiretroviral therapy. American Journal of Clinical Nutrition. 85: 333-345.

[7] Flynn K.C. (2001) Urban agriculture in Mwanza,Tanzania. 71: 666-691.

[8] Food and Agriculture Organization of the United Nations (2001) FAO's Initiative on Soaring Food Prices; Guide for Immediate Country Level Action. Rome. FAO. P.5.

[9] Food and Agriculture Organization of the United Nations (2007) Guidelines for measuring household and individual dietary diversity. Rome. Italy.

[10] Gordon D. (2005) Indicators of Poverty \& Hunger. In proceedings of the Expert Group Meeting on Youth Development Indicators. United Nations Headquarters. New York. 12th - 14th December 2005.

[11] Hoddinott J. and Yohaness Y. (2002) Dietary Diversity as a Household Food Security Indicator. Food and Nutrition Technical Assistance Project, Academy for Educational Development, Washington, D.C.

[12] Heredia A. Davis C. Amoroso A. et al. (2005) In vitro suppression of latent HIV-1 activation by vitamin E: potential clinical implications. Sheffield. UK. 19(8): 836-837.

[13] Kassam A. (2009) The spread of Conservation Agriculture: Justification,

[14] sustainability and uptake. University of Reading. UK.

[15] Koethe M.D. et al (2010) Association between Weight Gain and Clinical Outcomes Among Malnourished Adults Initiating Antiretroviral Therapy in Lusaka, Zambia. JAIDS 53(4) 507-513

[16] Kuchelmeister G. (1998) Urban agro-forestry; the over story. Agro-forestry journal. 87.

[17] Kutiwa S. (2010) Urban Agriculture in Low Income Households of Harare: An Adaptive Response to Economic Crisis. Vrije Universiteit Brussel. Belgium.

[18] Marsh R. and Talukder A. (1994) Production and consumption effects of the introduction of home gardening on target, interaction and control groups: a case study from Bangladesh. In Proceedings of the International Symposium on Systems-Oriented Research. Montpellier, France.

[19] Marsh R. (1994) Household food security through home gardening: evidence from Bangladesh and Central America. In Proceedings of The International Livestock Research Institute (ILRI)-Rockefeller Foundation Workshop. Addis Ababa. Ethiopia.

[20] Marston B. and De Cock K.M. (2004) Multivitamins, nutrition, and antiretroviral therapy for HIV in Africa. New England Journal of Medicine. 351:78-80. 
Mbiba B. (1993) Urban Agriculture, the Poor and Planners: A Harare case Study. In proceedings of the $10^{\text {th }}$ Inter Schools Conference on Development. Bartlett Graduate School. University College of London, UK.

[21] MDP-ESA (2009) Low Input gardening techniques for urban gardens. RUAF.

[22] Montessori V et al (2004) Adverse effects of antiretroviral therapy for HIV infection. Canadian Medical Association Journal. 170(2):229-238

[23] Mubvami T. (2011) Contributions of Urban Agriculture to Livelihoods. In proceedings of the Agriculture, Coordination and Working Group. Harare. Zimbabwe.

[24] Muchuweti et al. (2005) Heavy metal content of vegetables irrigated with mixtures of waste water and sewage sludge in Zimbabwe: Implication for Human Health, Agriculture, Ecosystems and the Environment. 112: 41-48.

[25] Mudimu G. Siziba S. and Hanyani B. (1998) Urban Agriculture, Food Security and the Environment : Socio Economics, Land Use Conflicts and Cultivator's. Department of Agricultural Economics and Extension.

[26] Mushayavanhu D. (2010) Policy brief on legalislative and policy issues on urban agriculture in Zimbabwe. MDP - ESA.

[27] National Aids Council (2012) Global AIDS response progress report. Government Printers. Harare.

[28] Nerad J. et al (2003) General nutrition management in patients infected with human immunodeficiency virus. Clinical Infectious Diseases Journal.36.

[29] Nyamanhindi (2011) Report on Urban Agriculture. In proceedings of the Agriculture Coordination and Working Group. Harare. Zimbabwe.

[30] Roberfroid S. (2010) Impact of Low Input Gardens on People Living with HIV in Chipinge District. Action Contra La Faim. Zimbabwe

[31] Swindale A. (2006) Household Dietary Diversity Score (HDDS) for Measurement of Household Food Access: Indicator Guide. Fanta project. Connecticut. USA.

[32] Toriro G. (2009) The Impact of the Economic Meltdown on Urban Agriculture in Harare. Urban Agriculture Magazine. Pg 26-27.

[33] World Health Organization (2005) Nutrition and HIV/AIDS. Geneva, World Health Organization. 